\title{
Diffusion Layer Growth Mechanism in ASPN Method Using an Iron Cage for St52 Steel
}

\author{
M. Kaini Salavat, M. Soltanieh, M. Hashemi Niasari \\ Department of Materials and Metallurgical Engineering \\ Iran University of Science and Technology, Tehran 16844, Iran \\ Mansour_soltanieh@iust.ac.ir; Mohammad_kiani@metaleng.iust.ac.ir \\ Mhashemi@iust.ac.ir
}

\begin{abstract}
The mechanism of diffusion layer growth in plasma nitrided coatings applied on a St52 steel using an active screen is investigated. The nitriding was performed at 450,500 and $550 \circ \mathrm{C}$ temperature nitriding times of 5,10 and $15 \mathrm{~h}$, in a gas mixture containing 20 vol. $\% \mathrm{H}_{2}: 80$ vol. $\% \mathrm{~N}_{2}$ and DC-pulsed plasma nitriding unit.

The surface, cross section and the thickness of diffusion of specimens was studied in terms of optical and scanning electron microscopy. According to the measurements of diffusion layer thickness, values of $\mathrm{Q}$ and $\mathrm{D}_{\mathrm{o}}$ for nitrogen diffusion in substrate were calculated as $50585(\mathrm{~J} / \mathrm{mol})$ and $4.11 \times 10^{-10}\left(\mathrm{~m}^{2} / \mathrm{s}\right)$, respectively. The variations of hardness depth during nitriding period were determined.
\end{abstract}

Keywords: Plasma nitriding, AISI St52 tool steel, Diffusion zone, Growth mechanism, Microhardness, Active Screen.

\section{Introduction}

Plasma nitriding process enhanced by an active screen is commonly used to improve corrosion behaviour and wear resistance of steels, titanium alloys, aluminum alloys, polymers and ceramics[1-6]. In this process, problems of conventional plasma nitriding like the edge effect are completely omitted since the plasma is produced on the screen not directly on the surface of sample [7-11].

During the plasma nitriding process of steels, the nitriding reaction takes place on the surface and in subsurface of substrate. As a result, two different structures have been identified, the so-called white or compound layer and the diffusion zone. The outermost layer is compound layer, and consists of one or two kind of iron nitrides $\left(\mathrm{Fe}_{4} \mathrm{~N}-\mathrm{Fe}_{2-3} \mathrm{~N}\right)$, depending on the process parameters. Below the white layer nitrogen atoms diffuses toward substrate which produces a diffusion zone [4, 5].

In diffusion zone, the diffusion thickness, $d$, is defined as the depth, can be estimated as $[12,13]$ :

$$
\mathrm{d}=\left(D_{\mathrm{e}} \cdot \mathrm{t}\right)^{1 / 2}
$$

where $D_{e}$ is the effective diffusion coefficient which depends on the diffusion and trapping (nitride formation) of $\mathrm{N}$. The constant $\mathrm{c}$ in Eq. (1) takes into account the onset time of the nitriding process, and $\mathrm{t}$ is the treatment time.

The temperature dependence of the effective diffusion coefficient $\left(D_{k}\right)$ can be approximately expressed in an Arrhenius form [14-16]:

$$
\mathrm{D}_{\mathrm{k}}=\mathrm{D}_{\mathrm{ko}} \exp \left(-\mathrm{Q}_{\mathrm{k}} / \mathrm{RT}\right)
$$

where $\mathrm{D}_{\mathrm{ko}}$ is so-called pre-exponential factor, $\mathrm{Q}_{\mathrm{k}}$ the activation energy for diffusion, $\mathrm{R}=8.3144\left(\mathrm{Jmol}^{-1} \mathrm{~K}^{-1}\right)$ the ideal gas constant, and $T$ the absolute temperature. With c coefficient and $D_{e}$ in Eq. (1) $D_{k o}$ and $Q_{k}$ for the diffusion of nitrogen in diffusion layer could be calculated.

In this study, the kinetics of diffusion layer produced by active screen plasma nitriding method on A St52 steel was determined. The effect of nitriding time and temperature on composition, structure and thickness of the nitrided layer was investigated by XRD optical and scanning electron microscope (SEM). The topographical evolution and surface roughness 
were studied by atomic force microscopy (AFM). It was found that there is a correlation between these properties and nitriding of the samples.

\section{Experimental Procedure}

A typical St52 boiler steel (chemical composition $0.27 \% \mathrm{C}, 0.6 \% \mathrm{Mn}, 0.18 \% \mathrm{Si}, 0.2 \% \mathrm{Cr}$ and $0.45 \% \mathrm{Cu}$, wt \%) were used in this study. Specimens were wire cut from the bars in the form of discs with $25 \mathrm{~mm}$ diameter and $10 \mathrm{~mm}$ height. All of the specimens were surface ground and polished using 60, 80, 120, 240, 400, 600, 800 and $1000 \mathrm{SiC}$ grit and $0.5 \mu \mathrm{m}$ alumina powder, respectively.

The polished specimens were placed on an insulated ceramic in an iron screen with $0.8 \mathrm{~mm}$ thickness, plasma nitrided in a pulsed DC plasma reactor. The plasma nitriding was performed with a $10 \mathrm{kHz}$ frequency and $60 \%$ duty cycle at 450 , 500 and $550{ }^{\circ} \mathrm{C}$ for 5,10 and $15 \mathrm{~h}$. The process parameters used in the nitriding chamber are shown in Table 1.

Table 1. Parameters related to screen and sample location.

\begin{tabular}{|l|l|l|l|l|l|l|}
\hline $\begin{array}{l}\text { Screen } \\
\text { Material }\end{array}$ & $\begin{array}{l}\text { Screen } \\
\text { diameter }\end{array}$ & $\begin{array}{l}\text { Screen } \\
\text { height }\end{array}$ & $\begin{array}{l}\text { Screen } \\
\text { hole } \\
\text { diameter }\end{array}$ & $\begin{array}{l}\text { Distance } \\
\text { between } \\
\text { screen holes }\end{array}$ & $\begin{array}{l}\text { Distance between } \\
\text { screen and sample } \\
\text { edge }\end{array}$ & $\begin{array}{l}\text { Distance between } \\
\text { screen and sample }\end{array}$ \\
\hline St 37 & $10 \mathrm{~cm}$ & $10 \mathrm{~cm}$ & $1 \mathrm{~cm}$ & $1 \mathrm{~cm}$ & $3 \mathrm{~cm}$ & $7 \mathrm{~cm}$ \\
\hline
\end{tabular}

X-ray diffraction (XRD) (Philips PW-1730) was used for phase composition analysis. VEGA II TESCAN scanning electron microscopy and optical microscopy (Carl-Zeiss, 4996387) were used for cross sectional microstructure of coatings. Cross-sectional microhardness profiles were obtained on polished surfaces, using a Buehler microhardness tester equipped with a Vickers indenter applying $50 \mathrm{~g}$ of load.

\section{Results and Discussion}

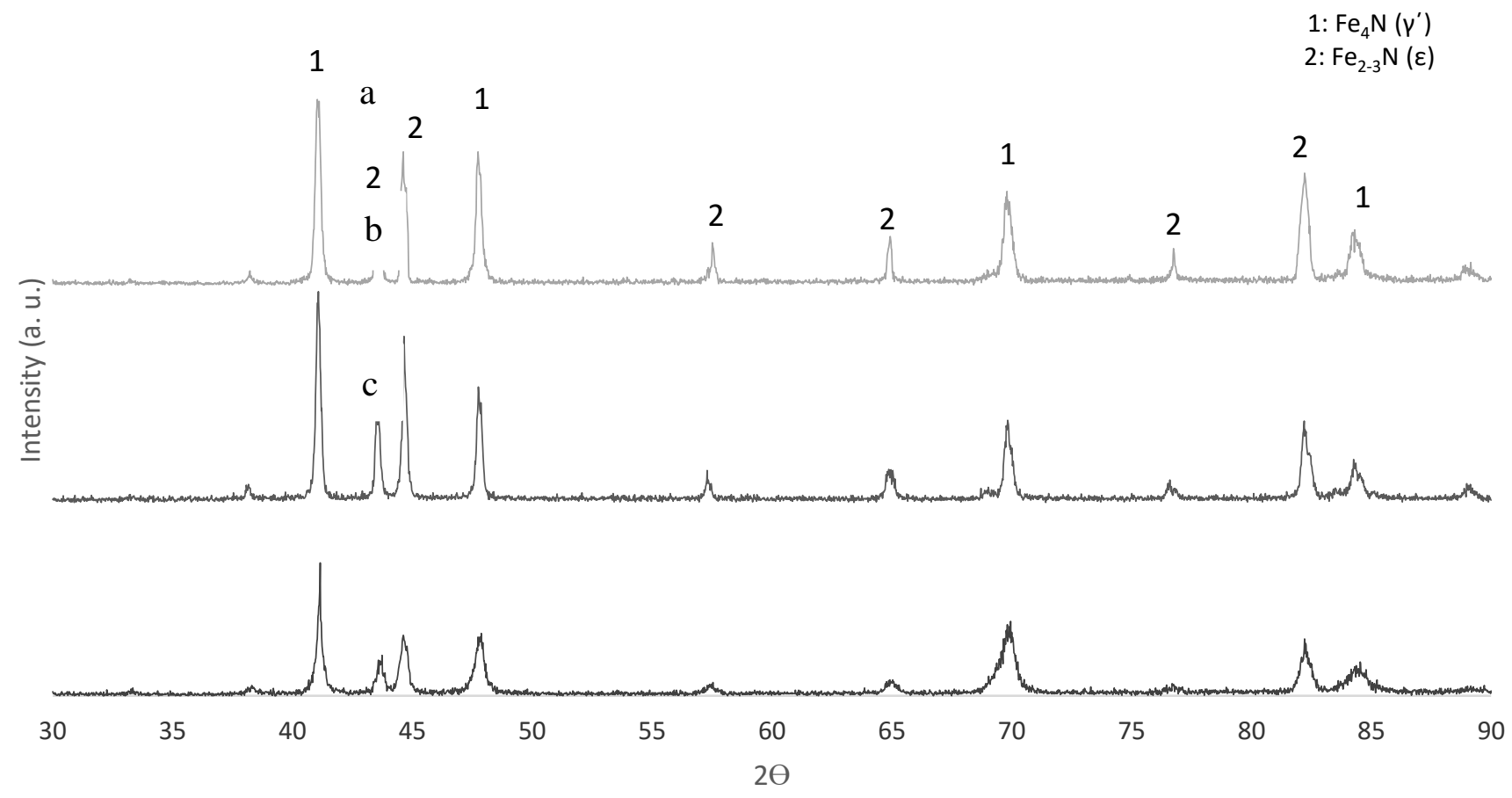

Fig. 1: The XRD patterns of active screen plasma nitrided samples for $10 \mathrm{~h}$ and $450^{\circ} \mathrm{C}$ (a), $500^{\circ} \mathrm{C}$ (b) and $550^{\circ} \mathrm{C}$ (c). 


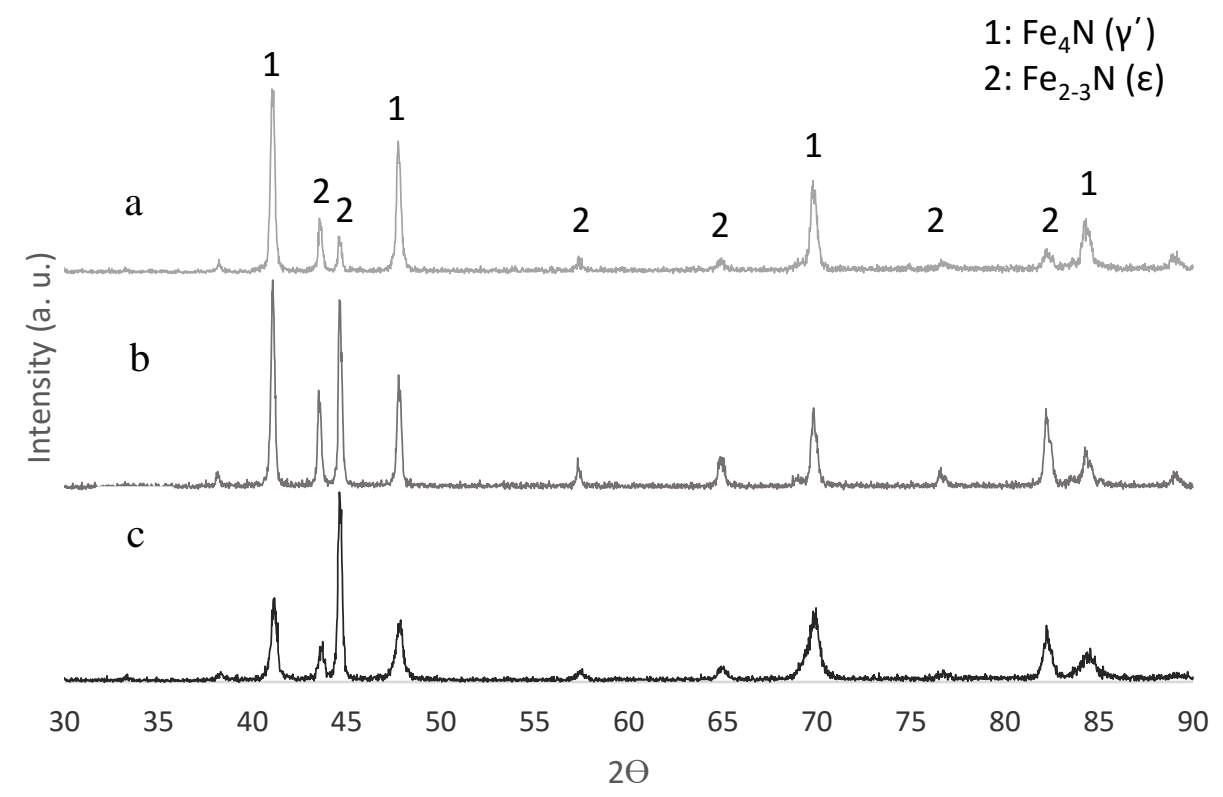

Fig. 2: The XRD patterns of active screen plasma nitrided samples at $500{ }^{\circ} \mathrm{C}$ for $5 \mathrm{~h} \mathrm{(a),} 10 \mathrm{~h}(\mathrm{~b})$ and $15 \mathrm{~h}(\mathrm{c})$.

The XRD patterns of the plasma nitrided samples treated at 450, 500 and $550{ }^{\circ} \mathrm{C}$ for $10 \mathrm{~h}$ are shown in Fig. 1, which indicate that the compound layer consists of $\gamma^{\prime}$ and $\varepsilon$ iron nitrides. In general, increasing the treatment temperature resulted in an increase in the intensity of the $\gamma^{\prime}$ and $\varepsilon$ phases. This may be explained by the increase in the compound layer thickness for an increase in the treatment temperature. In fact at higher temperature more $\mathrm{Fe}_{\mathrm{x}} \mathrm{N}$ particles would deposit from screen on the substrate surface which results more diffusion of nitrogen toward substrate. Fig. 2 shows the effect of plasma nitriding time on iron nitrides peak intensity. It may be noticed that intensity of $\gamma^{\prime}$ phase increases due to decomposition of $\mathrm{Fe}_{2-3} \mathrm{~N}$ to $\mathrm{Fe}_{4} \mathrm{~N}$ at longer treatment time.

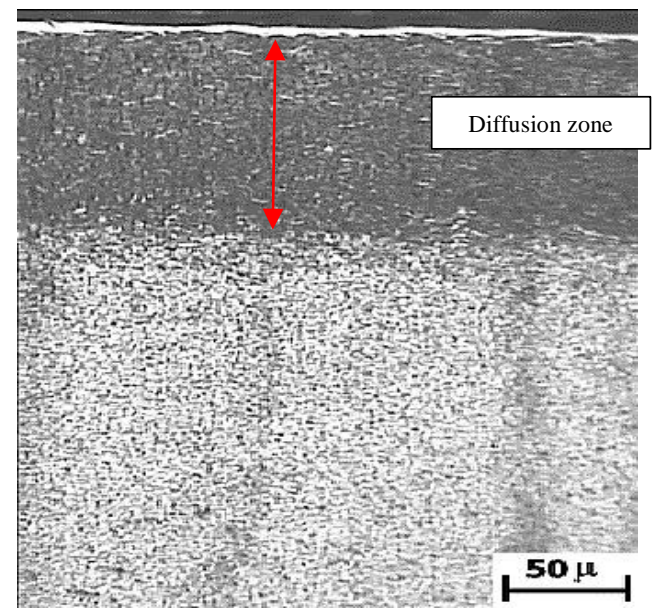

Fig. 3: The optical micrograph of typical specimen that is plasma nitrided at a gas mixture of $20 \% \mathrm{H}_{2}, 80 \% \mathrm{~N}_{2}$ at $500{ }^{\circ} \mathrm{C}$ for $10 \mathrm{~h}$.

The sample cross-section after plasma nitriding using an active screen at a gas mixture of $20 \% \mathrm{H}_{2}: 80 \% \mathrm{~N}_{2}$ and a temperature of $500{ }^{\circ} \mathrm{C}$ for $10 \mathrm{~h}$ are presented in Fig. 3. A diffusion zone and compound layer present on the surface can be seen. Fig. 4 shows the results of the compound layer thickness as a function of treatment temperatures. Increasing temperature causes thicker compound layer. The growth of the compound layer is controlled by diffusion of nitrogen through this layer [17]. At low treatment temperature, the diffusion coefficient of nitrogen atoms is low, therefore, the compound layer and 
diffusion layer are thin. Increasing treatment temperature results in an increase in the nitrogen diffusivity, leading to the formation of thicker layers.

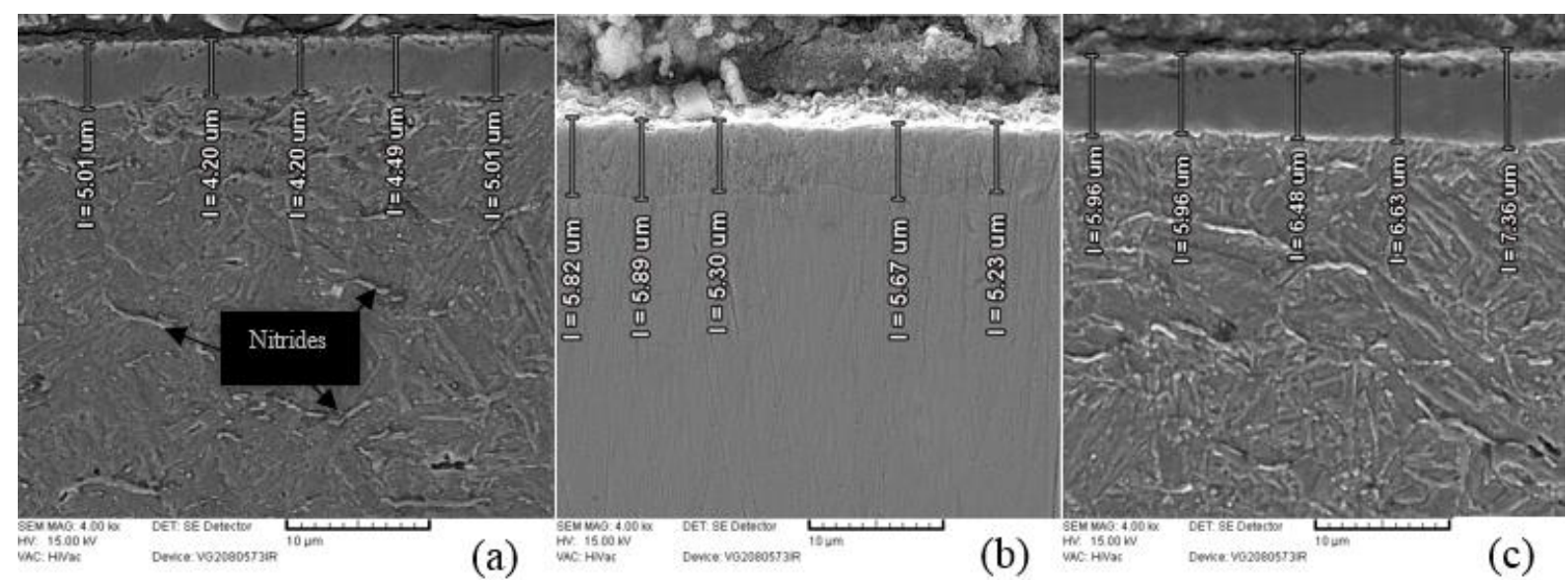

Fig. 4: SEM secondary electrons micrographs of the cross section specimen plasma nitrided at a gas mixture of $20 \% \mathrm{H}_{2}: 80 \% \mathrm{~N}_{2}$ at 450,500 and $550{ }^{\circ} \mathrm{C}$ for $10 \mathrm{~h}$.

The layers thickness assessed using OM and SEM cross sectional images is presented in Fig. 5. It is seen that by increasing the coating time, the layers thickness are increases which is due to the growth of the iron nitride particles descending from the top screen. Similar results have been reported by other researchers [18]. One of the important properties of active screen plasma nitriding method is enhancement of the coating thickness with nitriding time [1]. In conventional plasma nitriding, prolongation of time would decrease the coating thickness due to the direct formation of the plasma on the surface of the specimen and continuous surface sputtering, whereas in ASPN process the plasma forms on the screen. Thus, particles deposit continual on the surface leading to increase in coating thickness by treatment time. Moreover, the layers thickness is depended on temperature by Arrhenius equation [19]. In fact, increasing the processing temperature causes increment in diffusion constant which produces thicker diffusion zone.

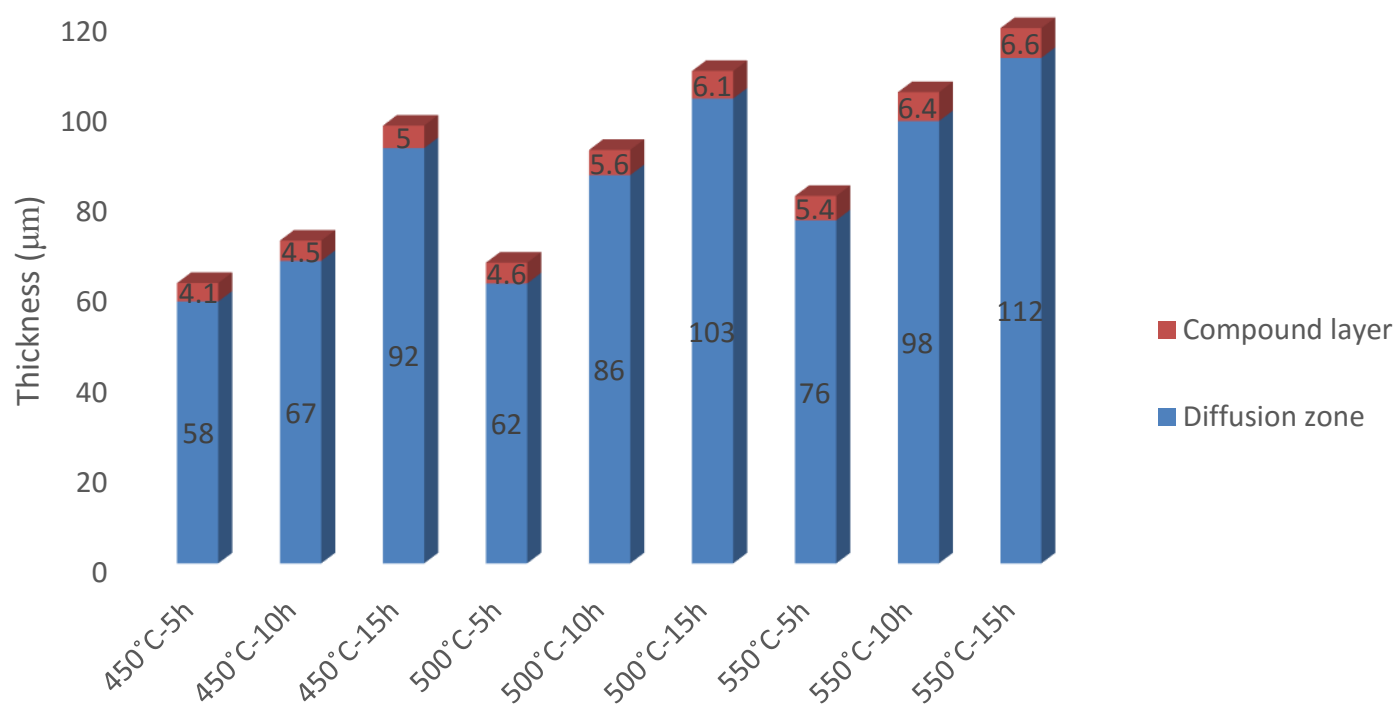

Fig. 5: The compound layer thickness and diffusion zone for nitrided samples at various plasma nitriding condition.

Cross sectional microhardness depth profile of samples nitrided at different nitriding time in 450,500 and $550{ }^{\circ} \mathrm{C}$ is illustrated in Fig. 6 (a-c). The results clearly show that near surface hardness is 3 times higher than that of un-nitrided 
substrate material. Surface hardening induced by nitriding, can be attributed to the solution of nitrogen atoms in the iron lattice which has the following effects: induces solid solution strengthening, formation of alloy nitrides and fine precipitates acting as obstacle against dislocations movement and development of compressive residual stress as a result of structural misfit because of the formation of interstitial solid solution and alloying element nitrides [20]. Moreover, Fig. 6 shows that at longer times, more atomic nitrogen diffuses from top surface towards substrate and hence expanding diffusion zone. Incremental decline in top surface microhardness could be due to the growth and coarsening of nitride precipitates which leads to lower precipitate density and lower hardness [15,21]. Diffusion depth and microhardness is enhanced by temperature at different treatment times. The higher temperature could increase the driving force of atomic nitrogen diffusion toward the substrate which may induce nitrided phase in a higher depth.
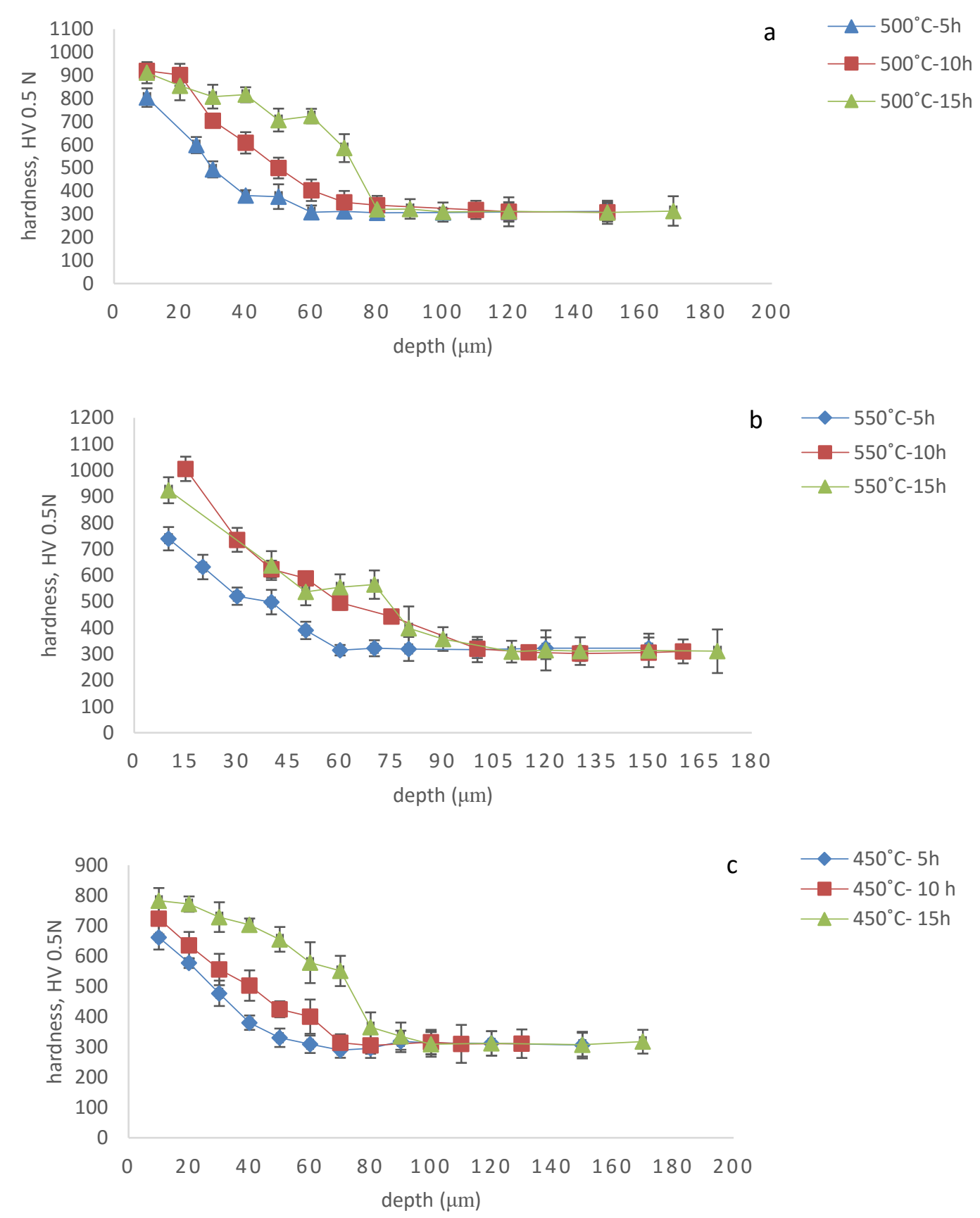

Fig. 6: Cross-sectional hardness-depth profile after plasma nitriding for 5,10 and $15 \mathrm{~h}$ at (a) $450^{\circ} \mathrm{C}$, (b) $500^{\circ} \mathrm{C}$, (c) $550^{\circ} \mathrm{C}$. 
In Fig. 7 the variation of diffusion depth estimated by OM, SEM and microhardness depth profile is drawn versus the nitriding time. A linear relationship was found between $\mathrm{d}$ and $\mathrm{t}^{0.5}$, as expected for a diffusion controlled process. The symbols represent the obtained results and the curves are obtained from fitting of Eq.1 on obtained results. Regarding the results of diffusion thickness measurements and with the usage of Arrhenius equation Eq. 2, values of $Q$ and $D_{o}$ for nitrogen diffusion in substrate were calculated as $50585(\mathrm{~J} / \mathrm{mol})$ and $4.11 \times 10-10\left(\mathrm{~m}^{2} / \mathrm{s}\right)$, respectively. Diffusion coefficient of nitrogen $\left(\mathrm{D}_{\mathrm{n}}\right)$ at $450^{\circ} \mathrm{C}$ would be calculated $3.7 \times 10^{-13}\left(\mathrm{~m}^{2} / \mathrm{s}\right)$ by substituting $\mathrm{Q}$ and $\mathrm{D}_{\mathrm{o}}$ values in Eq. $2.3 .7 \times 10^{-13}$.

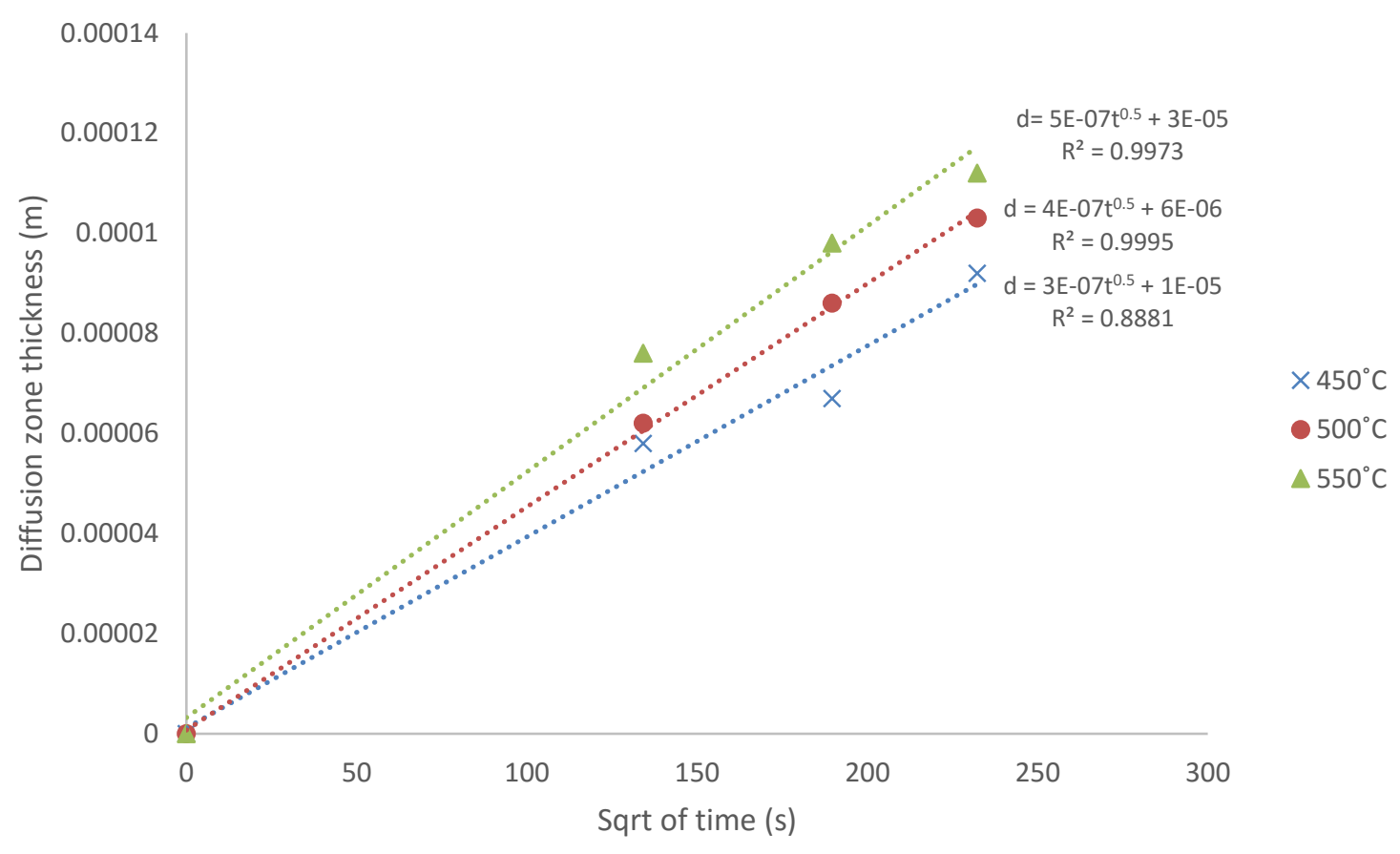

Fig. 7: Diffusion layer thickness as a function of plasma nitriding time.

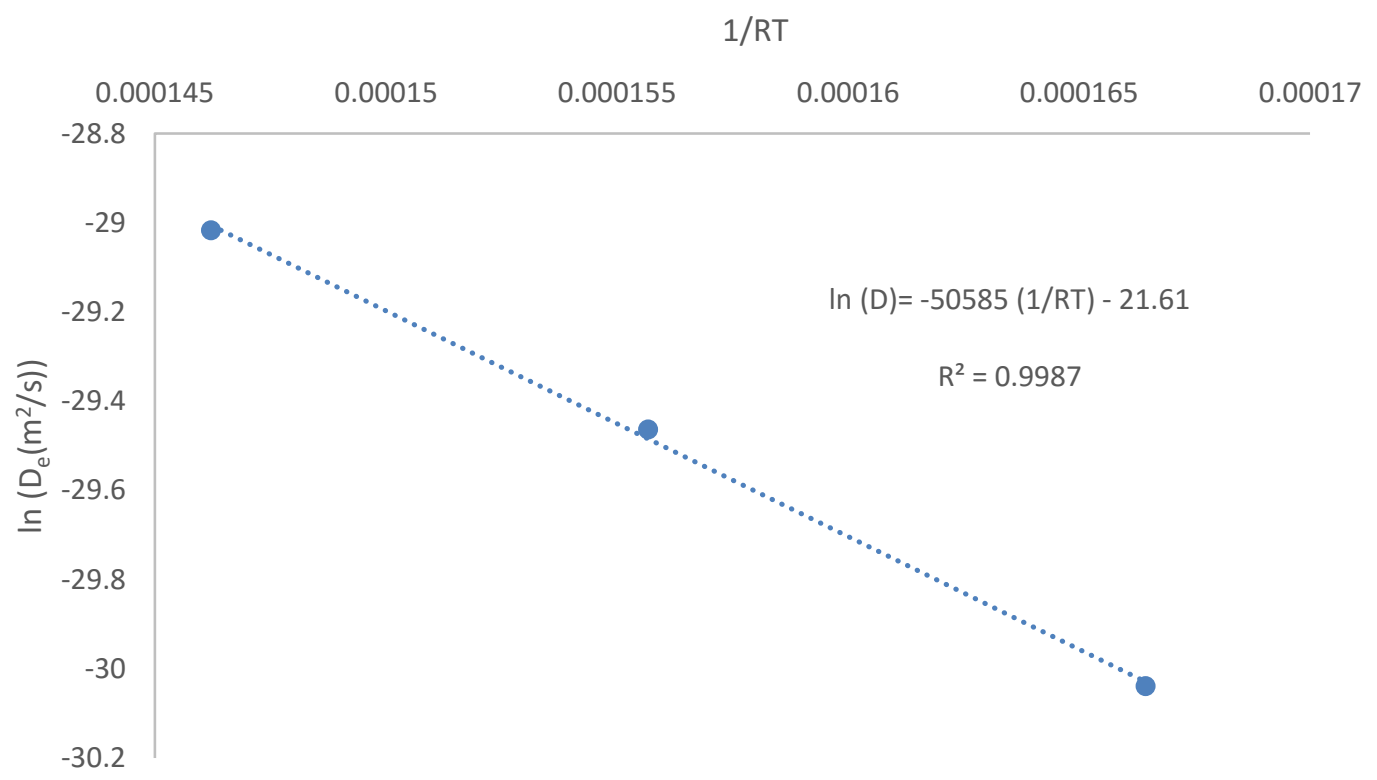

Fig. 8: Calculated values of $Q$ and $D_{k o}$ for nitrogen diffusion in substrate. 


\section{Conclusion}

The compositions of the coatings were studied by X-ray diffraction technique. The results showed that the compound layer was consisted mostly of dual phase $\gamma^{\prime}{ }_{-} \mathrm{Fe}_{4} \mathrm{~N}$ and ${ }^{\varepsilon}-\mathrm{Fe}_{2-3} \mathrm{~N}$. Increasing treatment temperature increased both $\gamma^{\prime} \mathrm{Fe}_{4} \mathrm{~N}$ and $\varepsilon_{-} \mathrm{Fe}_{2-3} \mathrm{~N}$ in the compound layer, however increasing the processing time increased only the $\gamma^{\prime}{ }_{-} \mathrm{Fe}_{4} \mathrm{~N}$ phase. Increasing treatment time and temperature increased both the compound and diffusion layer thicknesses. A linear relationship was found between the diffusion layer depth and the square root of the nitriding time, as expected for a diffusion controlled process. Values of $Q$ and $D_{0}$ for nitrogen diffusion in substrate for ASPN method were calculated as $50585(\mathrm{~J} / \mathrm{mol})$ and $4.11 \times 10^{-}$ ${ }^{10}\left(\mathrm{~m}^{2} / \mathrm{s}\right)$, respectively.

\section{References}

[1] A. Yazdani, M. Soltanieh, and H. Aghajani, "Active screen plasma nitriding of Al using an iron cage: Characterization and evaluation," Vacuum, vol. 122, pp. 127-134, 2015.

[2] Y. Sun and T. Bell, "Plasma surface engineering of low alloy steel," Materials Science and Engineering: A, vol. 140, pp. 419-434, 1991.

[3] N. Nayebpashaee, M. Soltanieh, and S. Kheirandish, "A Study on Formation and Growth Mechanism of Nitride Layers during Plasma Nitriding Process of Plastic Injection Mould Steel," Materials and Manufacturing Processes, 2015.

[4] C. Li and T. Bell, "Potential of plasma nitriding of polymer for improved hardness and wear resistance," Journal of materials processing technology, vol. 168, pp. 219-224, 2005.

[5] C. Li, H. Dong, and T. Bell, "A feasibility study of plasma nitriding of steel with an oxide layer on the surface," Journal of materials science, vol. 41, pp. 6116-6118, 2006.

[6] A. P. Kauling, G. V. Soares, C. A. Figueroa, R. V. de Oliveira, I. J. Baumvol, C. Giacomelli, et al., "Polypropylene surface modification by active screen plasma nitriding," Materials Science and Engineering: C, vol. 29, pp. 363-366, 2009.

[7] C. Li, T. Bell, and H. Dong, "A study of active screen plasma nitriding," Surface engineering, vol. 18, pp. 174-181, 2002.

[8] S. C. Gallo and H. Dong, "On the fundamental mechanisms of active screen plasma nitriding," Vacuum, vol. 84, pp. 321-325, 2009.

[9] C. Li, J. Georges, and X. Li, "Active screen plasma nitriding of austenitic stainless steel," Surface Engineering, vol. 18, pp. 453-457, 2002.

[10] C. Alves Jr, "Plasma nitriding: Foundations and applications," EDFRN, Natal, 2001.

[11] K. Nagatsuka, A. Nishimoto, and K. Akamatsu, "Surface hardening of duplex stainless steel by low temperature active screen plasma nitriding," Surface and Coatings Technology, vol. 205, pp. S295-S299, 2010.

[12] T. Clarke, A. da Silva Rocha, A. Reguly, and T. Hirsch, "In situ XRD measurements during plasma nitriding of a medium carbon steel," Surface and Coatings Technology, vol. 194, pp. 283-289, 2005.

[13] V. Dimitrov, J. D'Haen, G. Knuyt, C. Quaeyhaegens, and L. Stals, "A method for determination of the effective diffusion coefficient and sputtering rate during plasma diffusion treatment," Surface and Coatings Technology, vol. 99, pp. 234$241,1998$.

[14] P. Egert, A. Maliska, H. Silva, and C. Speller, "Decarburization during plasma nitriding," Surface and Coatings Technology, vol. 122, pp. 33-38, 1999.

[15] P. Corengia, G. Ybarra, C. Moina, A. Cabo, and E. Broitman, "Microstructural and topographical studies of DC-pulsed plasma nitrided AISI 4140 low-alloy steel," Surface and Coatings Technology, vol. 200, pp. 2391-2397, 2005.

[16] C. E. Pinedo and W. A. Monteiro, "On the kinetics of plasma nitriding a martensitic stainless steel type AISI 420," Surface and Coatings Technology, vol. 179, pp. 119-123, 2004.

[17] E. Roliński and G. Sharp, "The effect of sputtering on kinetics of compound zone formation in the plasma nitriding of 3\% Cr-Mo-V steel," Journal of materials engineering and performance, vol. 10, pp. 444-448, 2001.

[18] A. Nishimoto, H. Nii, R. Narita, and K. Akamatsu, "Simultaneous duplex process of TiN coating and nitriding by active screen plasma nitriding," Surface and Coatings Technology, vol. 228, pp. S558-S562, 2013.

[19] D. A. Porter, K. E. Easterling, and M. Sherif, Phase Transformations in Metals and Alloys, (Revised Reprint). CRC press, 2009. 
[20] M. Pellizzari, A. Molinari, and G. Straffelini, "Thermal fatigue resistance of gas and plasma nitrided 41CrAlMo7 steel," Materials Science and Engineering: A, vol. 352, pp. 186-194, 2003. 